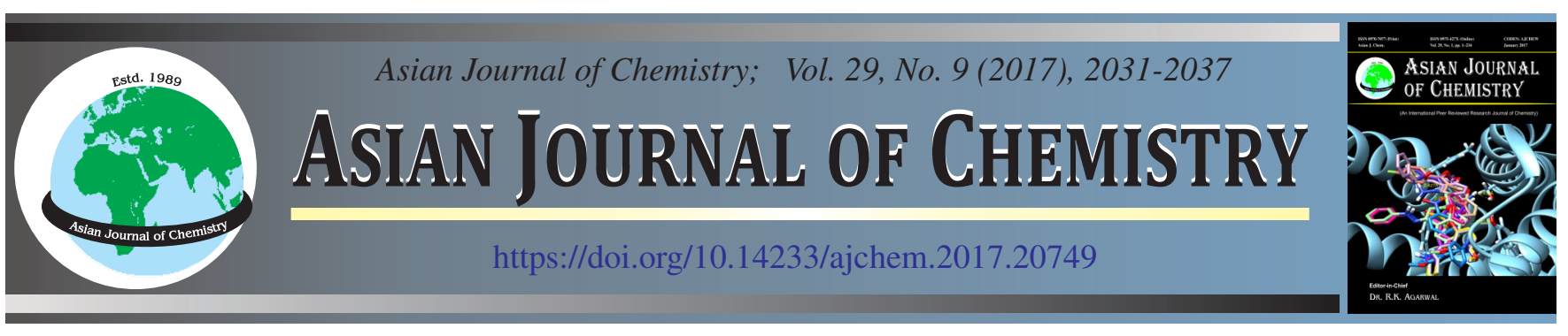

\title{
Development and Validation of High Performance Liquid Chromatography Method for Simultaneous Estimation of Curcuminoids from Rhizome Extracts
}

\author{
Amrin Begum ${ }^{1}$, Bolla Nagamani ${ }^{2}$ and Garapati SrideVi ${ }^{3, *}$
}

${ }^{1}$ CSIR-Indian Institute of Chemical Technology, Hyderabad-500007, India

${ }^{2}$ Department of Pharmaceutics, Viswanadha Institute of Pharmaceutical Sciences, Visakhapatnam-531 173, India

${ }^{3}$ Department of Chemistry, Andhra University College of Engineering for Women, Visakhapatnam-530 017, India

*Corresponding author: E-mail: sridevi_g_22@yahoo.co.in; sridevigarapati5@gmail.com

Received: 4 May 2017;

Accepted: 30 June 2017;

Published online: 15 July 2017;

AJC-18488

\begin{abstract}
A rapid and sensitive liquid chromatographic method is developed and validated for the simultaneous estimation of various curcuminoids. The method was used for the estimation of curcuminoids in commercially available dosage forms, bulk and naturally available root and rhizome extracts. The separation was performed on a Phenomenex ODS $2 \mathrm{C} 18(5 \mu \mathrm{m}, 15 \mathrm{~cm} \times 4.6 \mathrm{~mm})$ column. The composition of mobile phase is $50: 50 \%(\mathrm{v} / \mathrm{v})$ of acetonitrile and water containing $2 \% \mathrm{v} / \mathrm{v}$ glacial acetic acid operated on isocratic mode at a flow rate of $1.2 \mathrm{~mL} / \mathrm{min}$. Quantitation was achieved by HPLC-UV detection at $425 \mathrm{~nm}$. The specificity of the method (blank interference, interference from degradation products and interference from formulation excipients) was established. Degradation studies were performed in acid, alkaline, oxidative and photolytic stress conditions. The results showed that curcumin is prone to degradation in all aqueous media irrespective of $\mathrm{pH}$ of the solution. Also, in comparison to the standard curcuminoid composition $(83.5 \%$ curcumin, $14.5 \%$ dimethoxycurcumin and $1.5 \%$ bis-dimethoxycurcumin), large variation was observed in the root and rhizome powder extracts that were collected from commercial and crop samples.
\end{abstract}

Keywords: Curcumin, bis-Demethoxycurcumin, Demethoxycurcumin, Rhizome extracts, HPLC.

ᄂ - - - - - - - - - - - - - - - -

\section{INTRODUCTION}

Curcuminoids (Fig 1) are versatile compounds having a plethora of pharmacological activities [1]. Curcumin has been shown to exhibit antioxidant, anti-inflammatory [2-5], antimicrobial and anticarcinogenic [6-10] activities. Additionally, the hepato-and nephro-protective [11-13], thrombosis supressing [14], myocardial infarction protective [15-17]. hypoglycemic [18-21] and antirheumatic [22] effects of curcumin are also well established. Various animal models $[23,24]$ or human studies [25-28] proved that curcumin is extremely safe even at very high doses. For example, three different phase I clinical trials indicated that curcumin, when taken as high as $12 \mathrm{~g}$ per day, is well tolerated [26-28]. Similarly, the efficacy of curcumin in various diseases including cancer has been well established [29]. Several clinical studies dealing with the efficacy of curcumin in humans can also be cited $[1,30]$. The pharmacological safety and efficacy of curcumin makes it a potential compound for treatment and prevention of a wide variety of human diseases.

Due to its wide spectrum of pharmacological actions, curcumin is gaining increasing attention by the researchers. Curcumin has been proved to be less bioavailable [28-33].
The absorption, bio-distribution, metabolism and elimination studies of curcumin have, unfortunately, shown only poor absorption, rapid metabolism and elimination of curcumin as major reasons for poor bioavailability of this interesting polyphenolic compound [33-54].

Different strategies have been pursued to improve the absorption of curcumin including nanocrystals, emulsions, liposomes, self-assemblies and nanogels [55]. In animals, coadministration of curcumin with an extract obtained from the black pepper has been shown to increase the absorption (AUC) of curcumin by 1.5 -fold. Whereas, a complex of curcumin with phospholipids increased absorption by 3.4-fold [56] and a formulation of curcumin with a micellar surfactant (polysorbate) has been shown to increase the absorption of curcumin in mice 9-fold [57]. A micro emulsion system of curcumin, which consists of Capryol 90 (oil), Cremophor RH40 (surfactant) and Transcutol P aqueous solution (co-surfactant) has been shown to increase the relative absorption in rats by 22.6fold [58]. Polylactic-co-glycolic acid (PLGA) and PLGApolyethylene glycol (PEG) (PLGA-PEG) blend nanoparticles increased curcumin absorption by 15.6-and 55.4-fold, respectively, compared to an aqueous suspension of curcumin in rats [59]. 
<smiles>COc1cc(/C=C/C(=O)CC(=O)/C=C/c2ccc(O)c([O-])c2)ccc1O</smiles><smiles>COc1cc(/C=C/C(=O)CC(=O)/C=C/c2ccc(O)c(O)c2)ccc1O</smiles><smiles>Cc1cc(/C=C/C(=O)CC(=O)/C=C/c2ccc(O)c(O)c2)ccc1O</smiles>

Fig. 1. Structure of curcumin, bis-dimethoxycurcumin and dimethoxycurcumin

Food-grade formulations to enhance the absorption of curcumin have been studied in human clinical trials [60,61]. A proprietary formulation of curcumin has been developed retaining and utilizing more components of the raw turmeric root which are usually eliminated during extraction. The combination of curcuminoids and volatile oils of turmeric rhizome (CTR) resulted in a 6.9-fold increase in human absorption of curcumin [60]. The inclusion of curcumin in a lipophilic matrix (Phytosomes, Curcumin:Soy Lecithin:Microcrystalline Cellulose $1: 2: 2, \mathrm{CP}$ ) has been shown to increase the relative human absorption of curcumin by 19.2-fold [61]. A formulation made by mixing curcumin with glycerin, gum ghatti and water, followed by wet milling and dispersion by high-pressure homogenization has been shown the increase curcumin appearance in the blood by 27.6-fold [62]. A novel curcumin formulation which was made water soluble by dispersing curcumin and antioxidants (tocopherol and ascorbyl palmitate) on a watersoluble carrier such as polyvinyl pyrrolidone has been shown to have greater antidepressant action compared to conventional curcumin [63]. One study demonstrated that a combination of hydrophilic carrier, cellulosic derivatives and natural antioxidants significantly increases curcuminoid appearance in the blood in comparison to unformulated standard curcumin [64]. Although molecular mechanisms of action of curcumin are not fully understood, curcumin has proven to be a safe agent for the treatment of various ailments.

Various methods for the determination of curcuminoids were reported earlier. Thin layer chromatography based methods $[65,66]$, HPLC methods either using UV detection [67] or electrochemical detection and LC-MS detection [68,69] were reported. Most of these methods could only detect one single peak of curcumin. Asai \& Miyazawa [69] reported a method for the simultaneous estimation of curcumin, dimethoxycurcumin and bis-dimethoxycurcumin. A stability indicating HPLC-UV method was reported [70] for the determination of curcumin and celecoxib in nanoparticles formulation. The result showed that curcumin in solution was not stable and degraded after $1 \mathrm{~h}$ of stress studies. Curcumionoids are polyphenols and decomposed when exposed to high temperature [71].
Keeping in view of the wide spectrum of therapeutic action and growing research on these compounds, it is imperative to develop a specific and robust method. None of the methods reported till date established a robust and specific method to determine curcuminoids in presence of pharmaceutical excipients and degradation products. The objective of the present study is to determine a specific method for the determination of curcuminoids in bulk, formulation and available root and rhizome extracts. As part of the study, we have evaluated 5 branded formulations, 10 commercial food supplement samples and 5 different varieties of curcumin rhizome powders that were taken from different regions of India.

\section{EXPERIMENTAL}

Glacial acetic acid (SD Fine Chem Ltd), acetonitrile (HPLC grade, Merck ltd), were purchased from commercially available sources. Milli-Q water is obtained from the lab. Curcuminoids ( $>95 \% \mathrm{w} / \mathrm{w}$ ) is gifted from M/s Minerva Flavors and Fragrances Pvt Ltd. All other reagents and chemicals are of the highest analytical grade available.

The chromatographic system consisted of a Shimadzu Class VP Binary pump LC-10ATvp, SIL-10ADvp Auto sampler, CTO-10Avp Column Temperature Oven, SPD-10Avp UV-Visible Detector. All the components of the system are controlled using SCL-10Avp System Controller. Data acquisition was done using LC Solutions Version 1.23 software.

The mobile phase consisted of 50:50 \% (v/v) of acetonitrile and water containing $2 \% \mathrm{v} / \mathrm{v}$ glacial acetic acid operated on isocratic mode at a flow rate of $1.2 \mathrm{~mL} / \mathrm{min}$. Quantitation was achieved by HPLC-UV detection at $425 \mathrm{~nm}$. The injection volume is $20 \mu \mathrm{L}$. Acetonitrile is used as the rinsing solution. The Autosampler is operated at a constant temperature of $4{ }^{\circ} \mathrm{C}$ throughout analysis. The column is placed in a constant temperature oven operated at $24 \pm 2{ }^{\circ} \mathrm{C}$ throughout analysis.

\section{Preparation of solution}

Preparation of drug stock solutions: Stock solutions of curcumin $(1 \mathrm{mg} / \mathrm{mL})$ was prepared in methanol in a volumetric flask and labeled accordingly. The concentration of the stock is then calculated accounting to its \% purity on as is basis and actual amount weighed. The stock solutions are then stored in a refrigerator at $2-8{ }^{\circ} \mathrm{C}$ protected from light until further use.

Calibration standards and quality control samples: Aqueous calibration curve samples containing 6 non-zero standards were initially prepared using diluent solution $(70 \%$ $\mathrm{v} / \mathrm{v}$ methanol). The linear calibration ranged from 1.00-9.96 $\mu \mathrm{g} / \mathrm{mL}$. Quality control samples representing the low (LQC), medium (MQC) and high (HQC) were prepared such that their concentrations are within the range of the calibration curve.

Preparation of linear calibration standards: For the preparation of linearity curve, calibration standards were prepared in diluent solution to obtain calibration standards of values $1.00,1.99,3.98,5.98,7.97$ and $9.96 \mu \mathrm{g} / \mathrm{mL}$. An aliquot of $20 \mu \mathrm{L}$ of this solution was injected for the HPLC analysis.

Preparation of quality control samples: The quality control samples were prepared in diluent solution. The low quality control sample contained $2.49 \mu \mathrm{g} / \mathrm{mL}$, medium quality control sample contained $4.98 \mu \mathrm{g} / \mathrm{mL}$ and high quality control 
contained $7.47 \mu \mathrm{g} / \mathrm{mL}$ of curcuminoids. An aliquot of $20 \mu \mathrm{L}$ of this solution was injected for the HPLC analysis.

Preparation of sample solution: For the estimation in dosage forms, 20 capsules of each brand were taken and the powder is carefully transferred into a separate conical flask. An amount equivalent to the labeled claim (usually $500 \mathrm{mg}$ of curcuminoids for most formulations; few contained $300 \mathrm{mg}$ curcuminoids) was accurately weighed and taken in an extraction flask followed by $100 \mathrm{~mL}$ of methanol. This mixture was subjected to vigorous shaking for $30 \mathrm{~min}$ for complete extraction of the drug and then centrifuged at 5,000 rpm for $10 \mathrm{~min}$ (Biofuge Stratos Heraeus, Kendro Laboratory Products, Germany) to remove the excipients that were not soluble in the medium. The supernatant is filtered across $0.45 \mu \mathrm{m}$ nylon membrane filters and diluted suitably with diluent solution and $20 \mu \mathrm{L}$ of this solution was injected for HPLC analysis.

\section{Method validation}

System suitability: The system suitability was assessed by six replicate analyses of the medium quality control sample. The acceptance criterion was $\pm 2 \%$ for the per cent coefficient of variation $(\% \mathrm{CV})$ for the peak area and retention times for both drugs.

Detection and quantitation limits (sensitivity): Limits of detection (LOD) and limit of quantitation (LOQ) were estimated from the signal-to-noise ratio. The detection limit was defined as the lowest concentration level resulting in a peak area of three times the baseline noise. The quantitation limit was defined as the lowest concentration level that provided a peak area with a signal-to-noise ratio higher than 10 , with precision (\% CV) and accuracy (\% bias) within $\pm 10 \%$.

Linearity (calibration curve): The calibration curves were constructed with six non-zero standard concentrations ranging from $1.00-9.96 \mu \mathrm{g} / \mathrm{mL}$. The concentration $v s$. peak area of the drug was considered for plotting the linearity graph. The linearity was evaluated by linear regression analysis, which was calculated by the least square regression method.

Accuracy and precision: Accuracy of the assay method was determined for both intra-day and inter-day variations using the triplicate analysis of the quality control samples. Precision of the assay was determined by repeatability (intraday) and intermediate precision (inter day). Repeatability refers to the use of the analytical procedure within a laboratory over a short period of time that was evaluated by assaying the quality control samples during the same day. Intermediate precision was assessed by comparing the assays on different days ( 3 days).

Specificity: Specificity of the method was determined by subjecting the medium quality control sample solution to accelerated degradation in order to verify that none of the degradation products interfered with the quantitation of drug. The specificity of the method is established by calculating blank interference, interference from degradation products and excipients.

Stability: The stability of the drugs solution was determined using the quality control samples for short-term stability by keeping at room temperature for $12 \mathrm{~h}$ and then analyzing. Auto-sampler stability was determined by storing the samples for $24 \mathrm{~h}$ in the auto-sampler.
Stress testing: Stress testing of the drug substance can help identify the likely degradation products, the stability of the molecule and also validate the stability and specificity of the analytical procedures. For degradation studies, $500 \mathrm{mg}$ of curcuminoids was weighed and transferred to $100 \mathrm{~mL}$ volumetric flasks and dissolved in methanol (step 1). To this, suitable quantity of $1 \mathrm{~N} \mathrm{NaOH}$ (for alkaline degradation) or $1 \mathrm{~N} \mathrm{HCl}$ (for acid degradation) was added such the alkalinity or acidity of the final solution is $0.1 \mathrm{~N}$. The mixture is then placed in a water bath maintained at $60^{\circ} \mathrm{C}$ for $1 \mathrm{~h}$. For oxidative degradation, $1 \mathrm{~mL}$ of hydrogen peroxide (1/20) solution was added in step 1 . For photolytic degradation, solution prepared as in step 1 was exposed to UV light at $254 \mathrm{~nm}$ for $8 \mathrm{~h}$. The resultant solutions were separately diluted and injected for analysis.

\section{RESULTS AND DISCUSSION}

Spectral studies: Curcuminoids exhibit an absorption maximum at $425 \mathrm{~nm}$ and the maxima varies with the polarity of the solvent, $\mathrm{pH}$ of solution and the type of surfactant in solution. At $\mathrm{pH}$ above 6.5 curcuminoids are transformed into intense red colour with absorption maxima at $455 \mathrm{~nm}$. The varied presence of the two forms of curcumin in water-ethanol medium herein presented from visible spectra has been a new addition to the understanding of the solution behaviour of curcumin. In pure water $30.34 \%$ enol and $69.66 \%$ keto forms were found which rapidly changed into $85.5 \%$ enol and $14.5 \%$ keto forms in $40 \%$ ethanol [72]. The absorption maxima around $425 \mathrm{~nm}$ region is due to the enol group and that at 360 $\mathrm{nm}$ is due to the keto group. Since polar solvents facilitated the existence of enol form [73-75], the wavelength is selected at $425 \mathrm{~nm}$.

Selection of stationary phase and mobile phase: The most critical challenge involved in the method development process is the separation of curcuminoids. All the curcuminoids are closely related compounds with similar polarity. In most cases, we observed little or poor resolution between the curcuminoids. A Phenomenex ODS2 C18 $(150 \times 4.6,5 \mu)$ gave the best resolution among the curcuminoids.

Methanol and/or methanol-water mixtures alone could not cause the elution of the curcuminoids. Acetonitrile is chosen as the best solvent. However, altering the strength of the organic composition in the mobile phase led to earlier or farther retention times with no change in the relative retention times among the curcuminoids. In all our experiments we observed that solvents with higher strength are required for elution. Also inclusion of $2 \%$ glacial acetic acid in the mobile phase led to sharp and symmetric peaks. Acceptable tailing and resolution were obtained at a composition of 50:50\% (v/v) of acetonitrile and water containing $2 \% \mathrm{v} / \mathrm{v}$ glacial acetic acid operated on isocratic mode at a flow rate of $1.2 \mathrm{~mL} / \mathrm{min}$.

\section{Method validation}

System suitability: The \% CV of peak area and retention time for both drugs are within $2 \%$ indicating the suitability of the system. The efficiency of the column as expressed by number of theoretical plates for the six replicate injections and the USP tailing factor is given in Table-1. A representative chromatogram is given in Fig. 2. 


\begin{tabular}{ccccc}
\hline \multicolumn{5}{c}{ TABLE-1 } \\
SYSTEM SUITABILITY STUDY \\
\hline Sample ID & $\begin{array}{c}\text { Retention } \\
\text { time }\end{array}$ & $\begin{array}{c}\text { Peak } \\
\text { area }\end{array}$ & $\begin{array}{c}\text { Theoretical } \\
\text { plates }\end{array}$ & $\begin{array}{c}\text { Tailing } \\
\text { factor }\end{array}$ \\
\hline Curcumin 1 & 6.74 & 552690 & 37796.05 & 1.10 \\
Curcumin 2 & 6.76 & 568359 & 37566.59 & 1.10 \\
Curcumin 3 & 6.72 & 561032 & 38873.98 & 1.09 \\
Curcumin 4 & 6.68 & 560081 & 39406.73 & 1.10 \\
Curcumin 5 & 6.64 & 558171 & 38836.73 & 1.10 \\
Curcumin 6 & 6.65 & 553569 & 38387.35 & 1.11 \\
\hline Mean & 6.70 & 558983.67 & 38477.91 & 1.10 \\
SD & 0.05 & 5707.64 & 700.28 & 0.00 \\
CV (\%) & 0.77 & 1.02 & 1.82 & 0.42 \\
\hline
\end{tabular}

the best fit line (obtained as regression equation by using sum of least squares). Accuracy of each sample is measured using the formula:

$$
\text { Accuracy }(\%)=\frac{\text { Obtained concentration }}{\text { Calculated concentration }} \times 100
$$

The mean accuracy is also calculated and is reported as the average result of 6 replicate analyses. The precision of the method is then calculated for the 6 replicate injections. The results are tabulated in Table- 3 . The results demonstrate that the accuracy is within $95-105 \%$ of the nominal concentration with a precision less than $2 \%$.

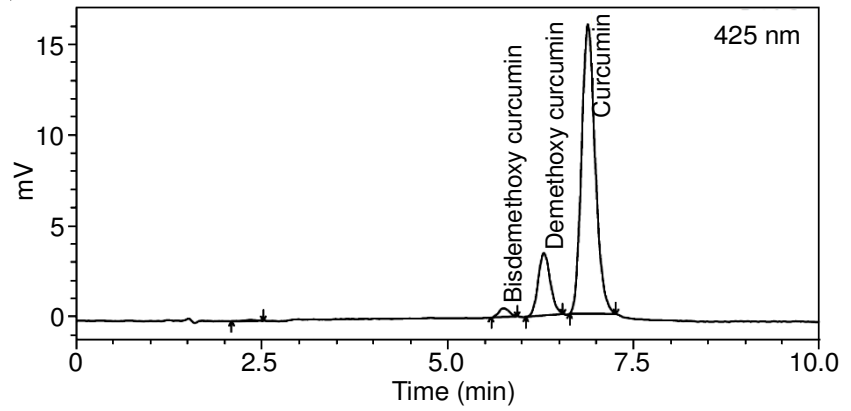

Fig. 2. Chromatogram showing the separation of curcuminoids

Linearity: The calibration curve constructed was evaluated by its correlation coefficient. The graph of concentration $v s$. peak area for both the drugs was linear. Standard deviation of the slopes and intercepts for the calibration curves generated on 6 different days. The correlation coefficient $\left(r^{2}\right)$ of all the calibration curves were consistent and greater than 0.995 (Table-2). A representative calibration curve is shown in Fig. 3.

TABLE-2

\begin{tabular}{|c|c|}
\hline \multicolumn{2}{|c|}{$\begin{array}{c}\text { TABLE-2 } \\
\text { REGRESSION ANALYSIS OF THE LINEARITY DATA }\end{array}$} \\
\hline Parameter & Curcumin $($ Mean \pm SD) \\
\hline Slope & $114567.45 \pm 113.45$ \\
\hline Intercept & $41006.8 \pm 546.15$ \\
\hline Correlation coefficient $\left(\mathrm{r}^{2}\right)$ & $0.9952 \pm 0.032$ \\
\hline
\end{tabular}

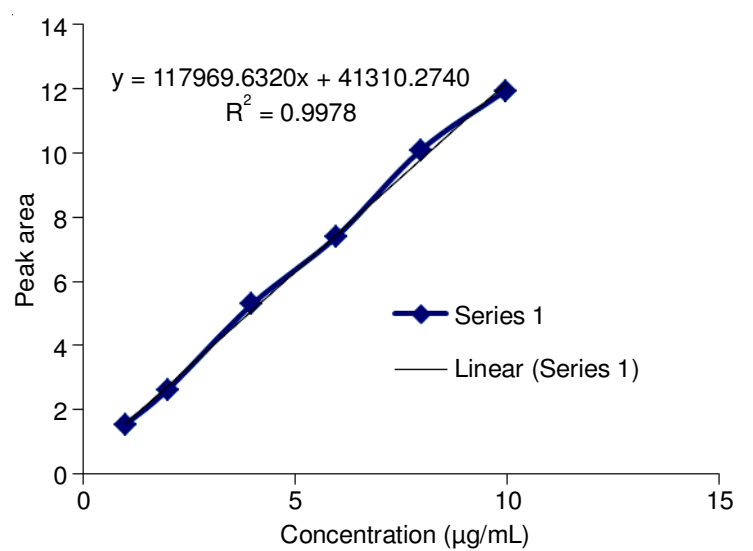

Fig. 3. Linear calibration curve of curcumin using HPLC-UV detection

Precision and accuracy: The accuracy of the method is determined at 3 levels by using quality control samples. These quality control samples are named as low quality control, medium quality control and high quality control. The concentration of each quality control sample is calculated from the equation of

\begin{tabular}{lccc}
\multicolumn{5}{c}{ TABLE-3 } \\
INTRA-DAY AND INTER-DAY ACCURACY AND \\
PRECISION OF HPLC ASSAY FOR CURCUMIN \\
\hline \multicolumn{4}{c}{ Nominal concentration $(\mu \mathrm{g} / \mathrm{mL})$} \\
\cline { 2 - 4 } & 2.49 & 4.98 & 7.47 \\
\hline \multicolumn{4}{c}{ Day 1} \\
\hline Mean accuracy & 99.01 & 99.16 & 100.63 \\
S.D & 0.29 & 0.37 & 1.35 \\
CV (\%) & 0.29 & 0.37 & 1.34 \\
\hline \multicolumn{4}{c}{ Day 2} \\
\hline Mean accuracy & 97.87 & 99.18 \\
S.D & 0.47 & 0.58 & 100.65 \\
CV (\%) & 0.48 & 0.58 & 1.23 \\
\hline \multicolumn{2}{c}{ Day 3 } \\
\hline Mean accuracy & 97.90 & 99.21 \\
S.D & 0.38 & 0.93 & 1.22 \\
CV (\%) & 0.38 & 0.94 & 1.23 \\
\hline
\end{tabular}

Specificity: The specificity of the method is demonstrated using blank sample, Sample containing curcuminoids, stress degradation studies and sample containing curcuminoids along with excipients. None of the excipients or degradation products interfered with the analysis of curcumin. It can be noted that there is a 5-7 \% degradation of curcuminoids due to photolytic degradation. Also, upon visual inspection we noticed that curcumin solutions turned to intense red colour in alkaline conditions due to the degradation. Curcumin in aqueous solutions degrades rapidly and the order of reaction increases with increase in $\mathrm{pH}$. The major degradation products are vanillin, acetone, feruloylmethane and ferulic acid [72,76,77]. Fig. 4 shows the absence of interference in the blank sample as compared to the lowest calibration standard.

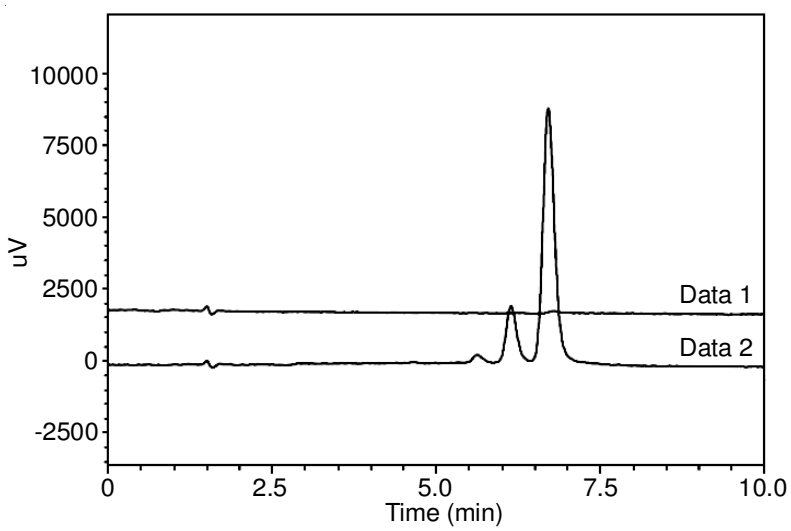

Fig. 4. Chromatograms depicting the blank interference compared against the lowest calibration standard (Data1-Blank sample, Data 2-lowest calibration standard) 
Limit of detection (LOD) and limit of quantitation (LOQ): The method was found to be sensitive as determined from the six replicate injections. The LOD of the method is $0.1 \mu \mathrm{g} / \mathrm{mL}$ and the LOQ of the method is $0.3 \mu \mathrm{g} / \mathrm{mL}$

Stability: Stability studies were performed for the stock solution and the stock dilutions. All stock solutions which were prepared in $100 \%$ methanol were stable at least for 60 days when stored in dark under refrigerated conditions. Stock dilutions were prepared in diluent solution. The stock dilution stability was evaluated at room temperature on bench top for $6 \mathrm{~h}$ (bench top), in auto-sampler for $24 \mathrm{~h}$ (Autosampler) and refrigerated at $4{ }^{\circ} \mathrm{C}$ for $24 \mathrm{~h}$ (refrigerated stability). The results of these stability studies are given in Tables $5 \mathrm{a}$ and $5 \mathrm{~b}$, where the percent ratios are within the acceptance range of 90-110\%.

Stress testing: The stress studies involving heat and acid, alkaline stress, UV-light and oxidation revealed that curcumin undergoes hydrolytic degradation under alkaline conditions. In aqueous solutions of neutral $\mathrm{pH}$ range curcumin undergoes $15 \%$ degradation per day while that in the alkaline range is about $70 \%$ per day. The degradation of curcumin in polar solvents is due to the disruption of excited state intramolecular proton transfer (EPIST). This EPIST process is more stabilized in the non-polar solvents resulting in a 6-membered chelate ring formation [78] (Table-4).

\begin{tabular}{|c|c|c|c|}
\hline \multicolumn{4}{|c|}{$\begin{array}{c}\text { TABLE-4 } \\
\text { SPECIFICITY DATA FOR CURCUMIN }\end{array}$} \\
\hline Sample name & \multicolumn{2}{|c|}{ USP plate count } & USP tailing \\
\hline Standard sample & \multicolumn{2}{|c|}{$20853.20 \pm 5.66$} & $1.16 \pm 0.03$ \\
\hline Oxidation sample & \multicolumn{2}{|c|}{$21540.86 \pm 53.03$} & $1.10 \pm 0.00$ \\
\hline Alkaline stress & \multicolumn{2}{|c|}{$19058.84 \pm 34.00$} & $1.19 \pm 0.01$ \\
\hline Acid stress & \multicolumn{2}{|c|}{$30118.77 \pm 57.28$} & $1.19 \pm 0.00$ \\
\hline UV stress & \multicolumn{2}{|c|}{$23201.23 \pm 31.11$} & $1.19 \pm 0.02$ \\
\hline \multicolumn{4}{|c|}{ *Each data is a the mean value of 6 replicate injections } \\
\hline \multicolumn{4}{|c|}{$\begin{array}{c}\text { TABLE-5 } \\
\text { BENCH TOP, AUTOSAMPLER AND REFRIGERATED } \\
\text { STABILITY FOR CURCUMIN DILUTIONS }\end{array}$} \\
\hline & \multicolumn{3}{|c|}{ Nominal concentration $(\mu \mathrm{g} / \mathrm{mL})$} \\
\hline & $\begin{array}{l}\text { Bench top } \\
\text { stability }(\%)\end{array}$ & $\begin{array}{l}\text { Autosampler } \\
\text { stability (\%) }\end{array}$ & $\begin{array}{l}\text { Refrigerated } \\
\text { stability }(\%)\end{array}$ \\
\hline Mean $(n=6)$ & 92.21 & 70.54 & 48.21 \\
\hline SD & 0.54 & 0.18 & 0.89 \\
\hline CV (\%) & 0.58 & 0.25 & 1.84 \\
\hline
\end{tabular}

Application of the method: Curcumin in various commercial rhizome powders were evaluated and the levels of various curcuminoids were also quantified (Table-6). Fig. 5 depicts the overlap spectra of curcuminoids analyzed in various rhizome powders. Rhizome powders with higher amounts of dimethoxycurcumin or bis-dimethoxycurcumin are more intensely yellow compared to $95 \%$ curcuminoid powders. In most of the formulation samples the percent of curcumin is more than $80 \%$ while that of bis-dimethoxycurcumin is around $5 \%$. The dimethoxycurcumin is between $12-16 \%$ in most of the commercial samples. In bulk samples we found that most of the naturally obtained curcuminoids are consistent. In the synthetic curcumin samples, the bis-dimethoxycurcumin and dimethoxycurcumin were totally absent. However, adulteration of natural curcumin with synthetic curcumin iswidespread and

\begin{tabular}{lccccc} 
TABLE-6 \\
LEVELS OF VARIOUS CURCUMINOIDS IN RHIZOMES \\
COLLECTED FROM DIFFERENT PARTS OF INDIA \\
\cline { 2 - 6 } & 1 & 2 & 3 & 4 & 5 \\
\hline & 17.36 & 39.88 & 37.96 & 14.14 & 1.94 \\
& 21.47 & 20.51 & 20.58 & 19.20 & 15.92 \\
\hline bis-Dimethoxycurcumin & 61.17 & 39.61 & 41.47 & 66.66 & 82.13 \\
\hline Dimethoxycurcumin & & & &
\end{tabular}

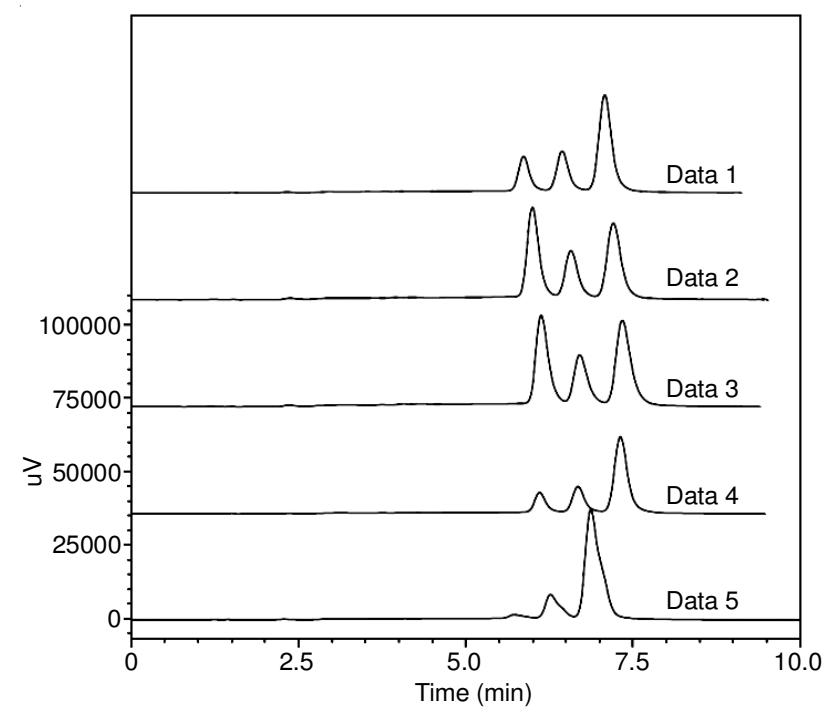

Fig. 5. Chromatograms depicting the variation in the levels of curcuminoids extracted from different rhizome powders. (Data1-Brand 1, Data 2Brand 2, Data 3-Brand 3, Data 4-Brand 4, Data 5-Brand 5)

can only be detected by radio carbon dating studies. The levels of curcuminoids in most commercial samples are consistent except those which are adopting the usage of rhizome powders in their formulation. It must be remembered that the ratio of the curcuminoid content is influenced by geographical and climatic conditions. We suggest a good vendor management only can bring in harmonization of the product. Most of the curcuminoids are within the $95-105 \%$ of their labeled claim. None of the ingredients interfered with the analyte peaks.

\section{Conclusion}

Although the usage of curcumin is widespread, its use as a therapeutic agent is growing rapidly. Several studies have reported beneficial effects of curcumin due to which there is an ever growing market for this golden spice. Till today, more than 120 different brands were being manufactured and sold worldwide as over the counter products. So there is a great necessity to harmonize the content and quality standards of the product. To measure the content of the curcuminoids in finished products, rhizome powders or in bulk material, a rapid and robust method for the determination of curcuminoids is greatly required. Accordingly, a simple robust and specific liquid chromatographic method for the estimation of curcuminoids in bulk, dosage forms and food supplements has been described. The method is very specific and free from interference arising from various excipients and degradation products. We found a large variation in the ratio of curcuminoids that were taken from various rhizome powders. Also it is widely reported that synthetic curcumin is being adulterated with natural curcumin. Specialized analytical techniques must be adopted to distinguish 
the natural and synthetic forms. Therefore thorough vendor management is highly recommended before formulating the rhizome powders as food supplements.

The sample preparation for analytical method must be exercised with high degree of caution and absorption maxima must be selected based on the solvent used. Curcumin in solution is prone to degradation by light and also influenced by $\mathrm{pH}$. Therefore sample analysis must be very rapid. The present method demonstrated a rapid analysis run time $(<10 \mathrm{~min})$ and we recommend to perform the analysis in dark. The method is validated as per ICH guidelines.

\section{REFERENCES}

1. B.B. Aggarwal, A. Kumar and A.C. Bharti, Anticancer Res., 23(1A), 363 (2003).

2. O.P. Sharma, Biochem. Pharmacol., 25, 1811 (1976); https://doi.org/10.1016/0006-2952(76)90421-4.

3. A.J. Ruby, G. Kuttan, K.D. Babu, K.N. Rajasekharan and R. Kuttan, Cancer Lett., 94, 79 (1995);

https://doi.org/10.1016/0304-3835(95)03827-J

4. Y. Sugiyama, S. Kawakishi and T. Osawa, Biochem. Pharmacol., 52, 519 (1996); https://doi.org/10.1016/0006-2952(96)00302-4.

5. R.C. Srimal and B.N. Dhawan, J. Pharm. Pharmacol., 25, 447 (1973); https://doi.org/10.1111/j.2042-7158.1973.tb09131.x.

6. W.C. Jordan and C.R. Drew, J. Natl. Med. Assoc., 88, 333 (1996).

7. G.B. Mahady, S.L. Pendland, G. Yun and Z.Z. Lu, Anticancer Res., 22(6C), 4179 (2002).

8. M.K. Kim, G.J. Choi and H.S. Lee, J. Agric. Food Chem., 51, 1578 (2003); https://doi.org/10.1021/jf0210369.

9. R.C. Reddy, P.G. Vatsala, V.G. Keshamouni, G. Padmanaban and P.N. Rangarajan, Biochem. Biophys. Res. Commun., 326, 472 (2005); https://doi.org/10.1016/j.bbrc.2004.11.051.

10. R. Kuttan, P. Bhanumathy, K. Nirmala and M.C. George, Cancer Lett., 29, 197 (1985); https://doi.org/10.1016/0304-3835(85)90159-4.

11. Y. Kiso, Y. Suzuki, N. Watanabe, Y. Oshima and H. Hikino, Planta Med., 49, 185 (1983); https://doi.org/10.1055/s-2007-969845.

12. N. Venkatesan, Br. J. Pharmacol., 124, 425 (1998); https://doi.org/10.1038/sj.bjp.0701877.

13. N. Venkatesan, D. Punithavathi and V. Arumugam, Br. J. Pharmacol., 129, 231 (2000); https://doi.org/10.1038/sj.bjp.0703067.

14. R. Srivastava, M. Dikshit, R.C. Srimal and B.N. Dhawan, Thromb. Res., 40, 413 (1985); https://doi.org/10.1016/0049-3848(85)90276-2.

15. M. Dikshit, L. Rastogi, R. Shukla and R.C. Srimal, Indian J. Med. Res., 101, 31 (1995)

16. C. Nirmala and R. Puvanakrishnan, Mol. Cell. Biochem., 159, 85 (1996); https://doi.org/10.1007/BF00420910.

17. C. Nirmala and R. Puvanakrishnan, Biochem. Pharmacol., 51, 47 (1996); https://doi.org/10.1016/0006-2952(95)02118-3.

18. M. Srinivasan, Indian J. Med. Sci., 26, 269 (1972).

19. P.S. Babu and K. Srinivasan, Mol. Cell. Biochem., 152, 13 (1995); https://doi.org/10.1007/BF01076459.

20. P.S. Babu and K. Srinivasan, Mol. Cell. Biochem., 166, 169 (1997); https://doi.org/10.1023/A:1006819605211.

21. N. Arun and N. Nalini, Plant Foods Hum. Nutr., 57, 41 (2002); https://doi.org/10.1023/A:1013106527829.

22. S.D. Deodhar, R. Sethi and R.C. Srimal, Indian J. Med. Res., 71, 632 (1980).

23. T.N. Shankar, N.V. Shantha, H.P. Ramesh, I.A. Murthy and V.S. Murthy, Indian J. Exp. Biol., 18, 73 (1980).

24. S. Qureshi, A.H. Shah and A.M. Ageel, Planta Med., 58, 124 (1992); https://doi.org/10.1055/s-2006-961412.

25. C.D. Lao, M.F. Demierre and V.K. Sondak, Expert Rev. Anticancer Ther, 6, 1559 (2006); https://doi.org/10.1586/14737140.6.11.1559.
26. C.D. Lao, M.T. Ruffin, D. Normolle, D.D. Heath, S.I. Murray, J.M. Bailey, M.E. Boggs, J. Crowell, C.L. Rock and D.E. Brenner, BMC Complement. Altern. Med., 6, 10 (2006); https://doi.org/10.1186/1472-6882-6-10.

27. A.L. Cheng, C.H. Hsu, J.K. Lin, M.M. Hsu, Y.F. Ho, T.S. Shen, J.Y. Ko, J.T. Lin, B.R. Lin, W. Ming-Shiang, H.S. Yu, S.H. Jee, G.S. Chen, T.M. Chen, C.A. Chen, M.K. Lai, Y.S. Pu, M.H. Pan, Y.J. Wang, C.C. Tsai and C.Y. Hsieh, Anticancer Res., 21(4B), 2895 (2001).

28. G. Shoba, D. Joy, T. Joseph, M. Majeed, R. Rajendran and P.S. Srinivas, Planta Med., 64, 353 (1998); https://doi.org/10.1055/s-2006-957450.

29. B.B. Aggarwal, C. Sundaram, N. Malani and H. Ichikawa, Adv. Exp. Med. Biol., 595, 1 (2007); https://doi.org/10.1007/978-0-387-46401-5_1.

30. C.H. Hsu and A.L. Cheng, Adv. Exp. Med. Biol., 595, 471 (2007); https://doi.org/10.1007/978-0-387-46401-5_21.

31. B. Wahlstrom and G. Blennow, Acta Pharmacol. Toxicol., 43, 86 (1978); https://doi.org/10.1111/j.1600-0773.1978.tb02240.x.

32. V. Ravindranath and N. Chandrasekhara, Toxicology, 16, 259 (1980); https://doi.org/10.1016/0300-483X(80)90122-5.

33. V. Ravindranath and N. Chandrasekhara, Drug Metab. Dispos., 27, 486 (1999).

34. S. Perkins, R.D. Verschoyle, K. Hill, I. Parveen, M.D. Threadgill, R.A. Sharma, M.L. Williams, W.P. Steward and A.J. Gescher, Cancer Epidemiol. Biomarkers Prev., 11, 535 (2002).

35. R.A. Sharma, S.A. Euden, S.L. Platton, D.N. Cooke, A. Shafayat, H.R. Hewitt, T.H. Marczylo, B. Morgan, D. Hemingway, S.M. Plummer, M. Pirmohamed, A.J. Gescher and W.P. Steward, Clin. Cancer Res., 10, 6847 (2004); https://doi.org/10.1158/1078-0432.CCR-04-0744.

36. K.Y. Yang, L.C. Lin, T.Y. Tseng, S.C. Wang and T.H. Tsai, Technol. Biomed. Life Sci., 853, 183 (2007); https://doi.org/10.1016/j.jchromb.2007.03.010.

37. K. Maiti, K. Mukherjee, A. Gantait, B.P. Saha and P.K. Mukherjee, Int. J. Pharm., 330, 155 (2007); https://doi.org/10.1016/j.ijpharm.2006.09.025.

38. T.H. Marczylo, R.D. Verschoyle, D.N. Cooke, P. Morazzoni, W.P. Steward and A.J. Gescher, Cancer Chemother. Pharmacol., 60, 171 (2007); https://doi.org/10.1007/s00280-006-0355-x.

39. S. Prasad, A.K. Tyagi and B.B. Aggarwal, Cancer Res. Treat., 46, 2 (2014); https://doi.org/10.4143/crt.2014.46.1.2.

40. G. Garcea, D.J. Jones, R. Singh, A.R. Dennison, P.B. Farmer, R.A. Sharma, W.P. Steward, A.J. Gescher and D.P. Berry, Br. J. Cancer, 90, 1011 (2004); https://doi.org/10.1038/sj.bjc.6601623.

41. G. Garcea, D.P. Berry, D.J. Jones, R. Singh, A.R. Dennison, P.B. Farmer, R.A. Sharma, W.P. Steward and A.J. Gescher, Cancer Epidemiol. Biomarkers Prev., 14, 120 (2005).

42. S.I. Hoehle, E. Pfeiffer, A.M. Solyom and M. Metzler, J. Agric. Food Chem., 54, 756 (2006); https://doi.org/10.1021/jf058146a.

43. G.M. Holder, J.L. Plummer and A.J. Ryan, Xenobiotica, 8, 761 (1978); https://doi.org/10.3109/00498257809069589.

44. C. Ireson, S. Orr, D.J. Jones, R. Verschoyle, C.K. Lim, J.L. Luo, L. Howells, S. Plummer, R. Jukes, M. Williams, W.P. Steward and A. Gescher, Cancer Res., 61, 1058 (2001)

45. P. Anand, A.B. Kunnumakkara, R.A. Newman and B.B. Aggarwal, Mol. Pharm., 4, 807 (2007); https://doi.org/10.1021/mp700113r.

46. S.I. Hoehle, E. Pfeiffer and M. Metzler, Mol. Nutr. Food Res., 51, 932 (2007); https://doi.org/10.1002/mnfr.200600283.

47. S.K. Sandur, M.K. Pandey, B. Sung, K.S. Ahn, A. Murakami, G. Sethi, P. Limtrakul, V. Badmaev and B.B. Aggarwal, Carcinogenesis, 28, 1765 (2007); https://doi.org/10.1093/carcin/bgm123.

48. E. Pfeiffer, S.I. Hoehle, S.G. Walch, A. Riess, A.M. Solyom and M. Metzler, J. Agric. Food Chem., 55, 538 (2007); https://doi.org/10.1021/jf0623283.

49. J.M. Kim, S. Araki, D.J. Kim, C.B. Park and N. Takasuka, Carcinogenesis, 19, 81 (1998); https://doi.org/10.1093/carcin/19.1.81. 
50. K. Okada, C. Wangpoengtrakul, T. Tanaka, S. Toyokuni, K. Uchida and T. Osawa, J. Nutr., 131, 2090 (2001).

51. M. Naito, X. Wu, H. Nomura, M. Kodama, Y. Kato, Y. Kato and T. Osawa, J. Atheroscler. Thromb., 9, 243 (2002); https://doi.org/10.5551/jat.9.243.

52. L. Pari and D.R. Amali, J. Pharm. Pharm. Sci., 8, 115 (2005).

53. P. Murugan and L. Pari, J. Basic Clin. Physiol. Pharmacol., 17, 231 (2006);

https://doi.org/10.1515/JBCPP.2006.17.4.231.

54. R.A. Sharma, H.R. McLelland, K.A. Hill, C.R. Ireson, S.A. Euden, M.M Manson, M. Pirmohamed, L.J. Marnett, A.J. Gescher and W.P. Steward, Clin. Cancer Res., 7, 1894 (2001).

55. M.M. Yallapu, M. Jaggi and S.C. Chauhan, Drug Discov. Today, 17, 71 (2012); https://doi.org/10.1016/i.drudis.2011.09.009.

56. A. Liu, H. Lou, L. Zhao and P. Fan, J. Pharm. Biomed. Anal., 40, 720 (2006); https://doi.org/10.1016/j.jpba.2005.09.032

57. H. Yu and Q. Huang, J. Agric. Food Chem., 60, 5373 (2012); https://doi.org/10.1021/jf300609p.

58. L. Hu, Y. Jia, F. Niu, Z. Jia, X. Yang and K. Jiao, J. Agric. Food Chem., 60, 7137 (2012); https://doi.org/10.1021/jf204078t.

59. N.M. Khalil, T.C. Nascimento, D.M. Casa, L.F. Dalmolin, A.C. Mattos, I. Hoss, M.A. Romano and R.M. Mainardes, Colloids Surf. B, 101, 353 (2013); https://doi.org/10.1016/j.colsurfb.2012.06.024.

60. B. Antony, B. Merina, V.S. Iyer, N. Judy, K. Lennertz and S. Joyal, Indian J. Pharm. Sci., 70, 445 (2008); https://doi.org/10.4103/0250-474X.44591.

61. J. Cuomo, G. Appendino, A.S. Dern, E. Schneider, T.P. McKinnon, M.J. Brown, S. Togni and B.M. Dixon, J. Nat. Prod., 74, 664 (2011); https://doi.org/10.1021/np1007262.

62. H. Sasaki, Y. Sunagawa, K. Takahashi, A. Imaizumi, H. Fukuda, T. Hashimoto, H. Wada, Y. Katanasaka, H. Kakeya, M. Fujita, K. Hasegawa and T. Morimoto, Biol. Pharm. Bull., 34, 660 (2011); https://doi.org/10.1248/bpb.34.660.

63. S.K. Kulkarni, K.K. Akula and J. Deshpande, Pharmacology, 89, 83 (2012); https://doi.org/10.1159/000335660.
64. R. Jäger, R.P. Lowery, A.V. Calvanese, J.M. Joy, M. Purpura and J.M. Wilson, Nutrition J., 13, 11 (2014); https://doi.org/10.1186/1475-2891-13-11.

65. V. Ravindranath and N. Chandrasekhara, Toxicology, 20, 251 (1981); https://doi.org/10.1016/0300-483X(81)90056-1.

66. N.F. Cooray, J. Natl. Sci. Found. Sri Lanka, 16, 39 (1988)

67. R.M. Smith and B.A. Witowska, Analyst (Lond.), 109, 259 (1984); https://doi.org/10.1039/an9840900259.

68. D.D. Heath, M.A. Pruitt, D.E. Brenner and C.L. Rock, J. Chromatogr. B Analyt. Technol. Biomed. Life Sci., 783, 287 (2003); https://doi.org/10.1016/S1570-0232(02)00714-6.

69. A. Asai and T. Miyazawa, Life Sci., 67, 2785 (2000); https://doi.org/10.1016/S0024-3205(00)00868-7.

70. D.B. Gugulothu and V.B. Patravale, Pharm. Anal. Acta, 3, 157 (2012); https://doi.org/10.4172/2153-2435.1000157.

71. G.W. Schieffer, J. Liq. Chromatogr. Rel. Technol., 25, 3033 (2002); https://doi.org/10.1081/JLC-120015889.

72. S. Mondal, S. Ghosh and S.P. Moulik, J. Photochem. Photobiol. B, 158, 212 (2016); https://doi.org/10.1016/j.jphotobiol.2016.03.004.

73. B. Boruah, P.M. Saikia and R.K. Dutta, J. Photochem. Photobiol. Chem., 245, 18 (2012); https://doi.org/10.1016/j.jphotochem.2012.07.004.

74. A. Dutta, B. Boruah, A.K. Manna, B. Gohain, P.M. Saikia and R.K. Dutta, Spectrochim. Acta A Mol. Biomol. Spectrosc., 104, 150 (2013); https://doi.org/10.1016/j.saa.2012.11.048.

75. L. Shen and H.-F. Ji, Spectrochim. Acta A, 67, 619 (2007); https://doi.org/10.1016/j.saa.2006.08.018.

76. Y.-J. Wang, M.-H. Pan, A.-L. Cheng, L.-I. Lin, Y.-S. Ho, C.-Y. Hsieh and J.-K. Lin, J. Pharm. Biomed. Anal., 15, 1867 (1997); https://doi.org/10.1016/S0731-7085(96)02024-9.

77. I. Stankovic, 61st Meeting of the Joint FAO/WHO Expert Committee on Food Additives (JECFA) Held in Rome, 2003, Chemical and Technical Assessment Report (2004).

78. C. Banerjee, S. Maiti, M. Mustafi, J. Kuchlyan, D. Banik, N. Kundu, D. Dhara and N. Sarkar, Langmuir, 30, 10834 (2014); https://doi.org/10.1021/la5023533. 